\title{
Endoscopic sclerotherapy compared with no specific treatment for the primary prevention of bleeding from esophageal varices. A randomized controlled multicentre trial [ISRCTN032 I 5899]
}

\author{
Henk R van Buuren*1, Marijke C Rasch², Piet L Batenburg3, \\ Clemens JM Bolwerk ${ }^{4}$, Jan J Nicolai ${ }^{5}$, Sjoerd DJ van der Werf ${ }^{6}$, \\ Joost Scherpenisse ${ }^{7}$, Lidia R Arends ${ }^{8}$, Jan van Hattum ${ }^{2}$, Erik AJ Rauws ${ }^{4}$ and \\ Solko W Schalm ${ }^{1}$
}

Address: ${ }^{1}$ Department of Gastroenterology and Hepatology, Erasmus MC, University Medical Center Rotterdam, The Netherlands, ${ }^{2}$ Department of Gastroenterology and Hepatology, University Hospital Utrecht, The Netherlands, ${ }^{3}$ Department of Internal Medicine, Zuiderziekenhuis, Rotterdam, The Netherlands, ${ }^{4}$ Department of Gastroenterology and Hepatology, Academic Medical Center, Amsterdam, The Netherlands, ${ }^{5}$ Department of Gastroenterology and Hepatology, Ziekenhuis Leyenburg, Den Haag, The Netherlands, ${ }^{6}$ Department of Internal Medicine, Westeinde Hospital, Den Haag, The Netherlands, ${ }^{7}$ Department of Gastroenterology, Reinier de Graaf Gasthuis, Delft, The Netherlands and ${ }^{8}$ Department of Epidemiology and Biostatistics, Erasmus MC, University Medical Center Rotterdam, The Netherlands

Email: Henk R van Buuren* - h.vanbuuren@erasmusmc.nl; Marijke C Rasch - wpkingma@worldonline.nl; Piet L Batenburg - pl@batenburg.be; Clemens JM Bolwerk - cl.bolwerk@wxs.nl; Jan J Nicolai - jjnicge@knmg.nl; Sjoerd DJ van der Werf - sdjvdwerfmd@hotmail.com;

Joost Scherpenisse - scherp@rdgg.nl; Lidia R Arends - arends@epib.fgg.eur.nl; Jan van Hattum - vanhattum@cs.com;

Erik AJ Rauws - e.a.rauws@amc.uva.nl; Solko W Schalm - s.schalm@erasmusmc.nl

* Corresponding author

Published: 15 August 2003

BMC Gastroenterology 2003, 3:22

This article is available from: http://www.biomedcentral.com/I47I-230X/3/22

(C) 2003 van Buuren et al; licensee BioMed Central Ltd. This is an Open Access article: verbatim copying and redistribution of this article are permitted in all media for any purpose, provided this notice is preserved along with the article's original URL.
Received: 31 December 2002

Accepted: 15 August 2003

\begin{abstract}
Background: Since esophageal variceal bleeding is associated with a high mortality rate, prevention of bleeding might be expected to result in improved survival. The first trials to evaluate prophylactic sclerotherapy found a marked beneficial effect of prophylactic treatment. These results, however, were not generally accepted because of methodological aspects and because the reported incidence of bleeding in control subjects was considered unusually high. The objective of this study was to compare endoscopic sclerotherapy (ES) with nonactive treatment for the primary prophylaxis of esophageal variceal bleeding in patients with cirrhosis.

Methods: I 66 patients with esophageal varices grade II, III of IV according to Paquet's classification, with evidence of active or progressive liver disease and without prior variceal bleeding, were randomized to groups receiving ES $(n=84)$ or no specific treatment $(n=82)$. Primary end-points were incidence of bleeding and mortality; secondary end-points were complications and costs.

Results: During a mean follow-up of 32 months variceal bleeding occurred in $25 \%$ of the patients of the ES group and in $28 \%$ of the control group. The incidence of variceal bleeding for the ES and control group was $16 \%$ and $16 \%$ at I year and $33 \%$ and $29 \%$ at 3 years, respectively. The I-year survival rate was $87 \%$ for the ES group and $84 \%$ for the control group; the 3 -year survival rate was $62 \%$ for each group. In the ES group one death occurred as a direct consequence of variceal bleeding compared to 9 in the other group ( $p=0.01$, log-rank test). Complications were comparable for the two groups. Health care costs for patients assigned to ES were estimated to be
\end{abstract}


higher. Meta-analysis of a large number of trials showed that the effect of prophylactic sclerotherapy is significantly related to the baseline bleeding risk.

Conclusion: In the present trial, prophylactic sclerotherapy did not reduce the incidence of bleeding from varices in patients with liver cirrhosis and a low to moderate bleeding risk. Although sclerotherapy lowered mortality attributable to variceal bleeding, overall survival was not affected. The effect of prophylactic sclerotherapy seems dependent on the underlying bleeding risk. A beneficial effect can only be expected for patients with a high risk for bleeding.

\section{Background}

About one-third of patients with liver cirrhosis and varices are likely to undergo hemorrhage during their lifetime [15 ]. The average mortality due to the first variceal bleeding has been estimated to be about $30-50 \%[1,6,7]$. Variceal bleeding therefore represents a frequent cause of death and one might expect survival to improve if bleeding could be prevented.

The potential of primary prevention of variceal bleeding to improve prognosis is dependent on the severity of the underlying disease. There is a close relationship between (risk of) bleeding and degree of liver failure. Often bleeding precipitates or exacerbates liver failure, while deteriorating liver function frequently precedes variceal bleeding. Obviously, prevention of bleeding in end-stage disease is unlikely to affect prognosis. For patients with a relatively preserved liver function, however, prevention of bleeding might improve prognosis, by reducing mortality due to exsanguination as well as from the complications frequently encountered after variceal bleeding, including hepatorenal syndrome, infections and multi-organ failure.

The first type of primary prophylaxis evaluated was the portacaval shunt [3-5]. Although shunt surgery reduced the frequency of bleeding, the rate of both mortality and encephalopathy was increased. Data on other prophylactic surgical procedures are limited and do not allow conclusions [8].

The first reports on the use of prophylactic sclerotherapy suggested that this procedure not only significantly reduced the incidence of variceal bleeding [9-12] but also lowered overall mortality $[10,12]$. However, the results of these trials were disputed, mainly because the reported bleeding risk for control patients in some studies was considered exceptionally high and treatment of acute variceal bleeding episodes was not the same for the two treatment groups $[1,13]$.

The aim of the present multicentre study was to evaluate the effect of endoscopic sclerotherapy for the primary prevention of variceal bleeding in an adequate number of patients with cirrhosis and esophageal varices, with uniform treatment of variceal bleeding in both groups.

\section{Methods \\ Patient selection}

Eligible patients were adults with endoscopically documented grade II, III or IV esophageal varices [14], absence of prior bleeding from varices, evidence of active and/or progressive liver disease (e.g. as indicated by repeatedly elevated serum transaminases or increasing serum bilirubin levels or development of ascites within the past year) or documented increase in the size of esophageal varices; all patients gave informed consent. Patients were excluded for the following reasons: use of $\beta$-blockers and nitrates, malignancy, hemophilia, age older than 70-75 years, no opportunity for follow-up visits.

\section{Centers, study design, randomization and informed consent}

This was a multicentre randomized controlled trial that started on 1 May 1986. Patients were included until May 1993 and followed until November 1993. Participating centers (number of patients in parentheses) were the University Hospital Rotterdam (coordinating center)(81); the University Hospital Utrecht (25); the Zuiderziekenhuis, Rotterdam (17); the Academic Medical Center, Amsterdam (15); the Ziekenhuis Leyenburg (12) and Westeinde Hospital (10), The Hague; and the Reinier de Graaf Gasthuis, Delft (6).

Randomization was performed according to Zelen's prerandomization design [15]. After assessment of eligibility, patients were randomized and provided with oral and written information; they were then asked to participate and give informed consent. This procedure was expected to facilitate patient entry, being considered defensible and appropriate taking into account the marked difference between the two treatment options [16]. The medical ethical committee of one center did not approve of the prerandomization method; in this center the conventional procedure was followed.

Treatment was assigned centrally, by telephone contact or by visiting the trial office, using opaque, serially numbered sealed envelopes. Patients were stratified for center 
and severity of liver disease according to the Child-Pugh classification [17]. Follow-up started at the time of randomization. Patients gave written informed consent. The medical ethical committees of the participating centers approved the trial.

\section{Endoscopic sclerotherapy}

Experienced endoscopists performed all procedures using fiber or video-endoscopes. Patients received intravenous sedation consisting of $0.075-0.2 \mathrm{mg}$ midazolam $/ \mathrm{kg}$. Varices were injected at multiple sites with $0.5-3 \mathrm{ml}$ ethoxysclerol (polidocanol) $1 \%$ or $2 \%$ (Kreussler, Germany), proceeding upwards from the gastroesophageal junction. The maximum injection volume was $35 \mathrm{ml} / \mathrm{ses}-$ sion. Patients were hospitalized for the first sclerotherapy session. Successive treatments were planned on an outpatient basis at 3-week intervals until variceal obliteration was achieved. The aim of sclerotherapy was complete variceal eradication. Subsequently control examinations were performed at 6-month intervals. Recurrent varices were treated. When eradication was established on two subsequent visits further control examinations were scheduled at yearly intervals.

\section{Entry and follow-up procedures}

Before randomization, all patients underwent upper gastrointestinal endoscopy. Esophageal varices were classified according to Oberhammer and Paquet [14]. Meetings of participants were organized to review and standardize diagnostic aspects. The Child-Pugh classification system [17] was used as a measure of functional hepatic reserve. General care of the patients in both groups was identical and involved clinical and biochemical assessment at 3month intervals.

\section{Definition of key events; management of rebleeding and complications}

We used international consensus definitions of variceal bleeding and variceal rebleeding. Variceal bleeding was diagnosed when endoscopy, performed within 24 hours after occurrence of hematemesis or melena, showed active variceal bleeding, signs of recent bleeding ("white nipple sign" or adherent clot) or showed varices without another potential source of bleeding in the presence of blood in the stomach. [18]. For both groups, the standard therapy for variceal bleeding was resuscitation followed by endoscopic sclerotherapy according to the methods described above, but at intervals of one week until variceal obliteration was achieved. Subsequently, follow-up examinations were performed after 3 months, and then at 6, 9 and finally 12 -month intervals. Balloon tamponade was performed when variceal bleeding was not controlled by ES for a period of up to 24 hours and was followed by renewed ES. Therapy for patients with persistent or recurrent variceal bleeding was not defined and decisions were left to the discretion of the individual hospital departments. Variceal obliteration was defined as variceal thrombosis and absence of variceal blood flow as assessed by needle puncture. Variceal eradication was defined as visual absence of variceal columns. Procedure-related mortality was defined as death within 30 days of ES. Esophageal mucosal ulcers after ES were not regarded as a complication unless they caused symptoms, including bleeding and pain.

\section{Analysis of costs}

An estimation of the direct medical costs was made by comparing the time spent in the intensive care unit and the ordinary ward, the number of visits to the outpatient department and the number of upper gastrointestinal endoscopies, including sclerotherapy procedures. Only patients admitted to the University Hospital Rotterdam were included. Indirect costs, e.g. economic loss due to inability to work, were not taken into consideration.

\section{Statistics}

A sample size calculation was performed assuming a 30\% and $10 \%$ incidence of bleeding 3 years after entry for the control and ES groups, respectively. To detect this difference with a significance level (alpha) of 0.05 and a power of $90 \%$, and using a two-tailed test, we calculated that we needed to recruit 79 patients for each treatment group. Analyses were performed on an intent-to-treat basis. The primary end-points of this study were variceal bleeding and mortality. Secondary end-points were complications and health-care costs.

Bleeding and mortality were analyzed using the KaplanMeier method. Differences between groups were compared by means of the log-rank test. The $\chi 2$ test was used to analyze differences between groups for qualitative data. Paired and unpaired t-tests, or their non-parametric equivalents where appropriate, were used for quantitative data. For analyzing the relationship between baseline bleeding risk and the effect of prophylactic sclerotherapy on the risk of a first variceal bleeding, as reported in the literature and including data of the present trial, the method proposed by Arends et al [19]was used. A twotailed $\mathrm{p}$-value $=0.05$ was considered significant.

\section{Results}

Of the 166 patients enrolled in the study 84 were randomized to undergo ES and 82 to the control group (Figure $1)$. Patient characteristics of the two groups were comparable (table 1). Mean follow-up was $32 \pm$ SD 25 (range 0.1 - 88.5) months; for the ES group $30 \pm 23$ months and for controls $34 \pm 27$ months. Follow-up was incomplete for 11 (ES group 7) patients due to removal, emigration or other reasons. For these cases data were censored at the time of the last visit. In all cases, however, efforts were 


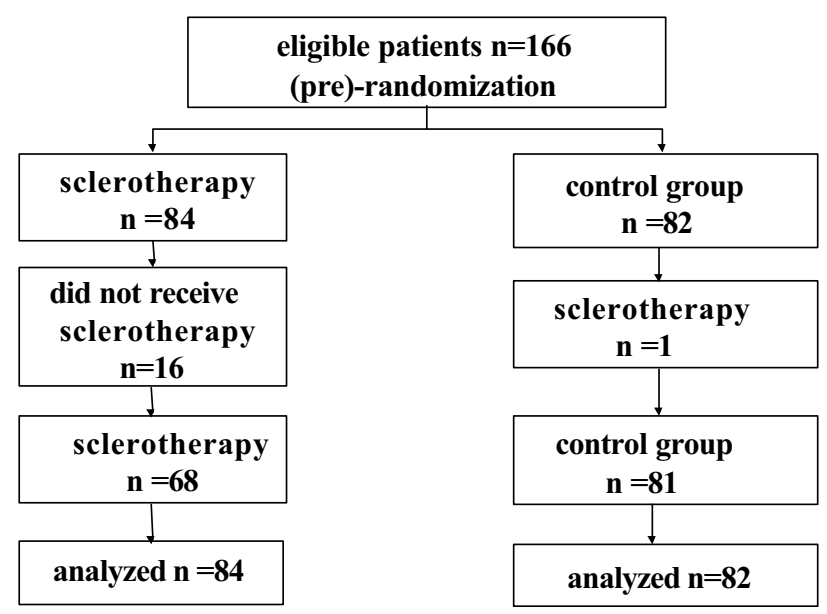

Figure I

Trial profile.

Table I: Patient characteristics at entry

\begin{tabular}{|c|c|c|}
\hline Characteristic & $\begin{array}{l}\text { Sclerotherapy } \\
n=84\end{array}$ & Controls $n=82$ \\
\hline Age & $56(23-76)$ & $55(20-72)$ \\
\hline $\operatorname{Sex}(M / F)(n)$ & $46 / 38$ & $49 / 33$ \\
\hline \multicolumn{3}{|l|}{ Diagnosis } \\
\hline Alcoholic liver disease & 41 & 40 \\
\hline Hepatitis B/C & 24 & 21 \\
\hline PBC/PSC & 11 & 8 \\
\hline Other & 24 & 31 \\
\hline Child-Pugh class $A / B / C(n)$ & $44 / 32 / 8$ & $47 / 25 / 10$ \\
\hline Child-Pugh score & $6(5-12)$ & $6(5-13)$ \\
\hline \multicolumn{3}{|l|}{ Esophageal varices } \\
\hline grade II & 47 & 42 \\
\hline grade III & 38 & 40 \\
\hline grade IV & 15 & 18 \\
\hline Ascites & 44 & 37 \\
\hline \multicolumn{3}{|l|}{ Laboratory } \\
\hline Bilirubin $(\mu \mathrm{mol} / \mathrm{l})$ & $27(7-429)$ & $27(7-2 \mid 7)$ \\
\hline Albumin $(g / l)$ & $36(18-48)$ & $35(23-47)$ \\
\hline AT-III (IE/I) & $0.7(0.22-1.45)$ & $0.7(0.24-1.32)$ \\
\hline ASAT (U/I) & $44.5(12-264)$ & $49(12-373)$ \\
\hline
\end{tabular}

Results are expressed as percentages and medians with ranges, unless otherwise indicated. Normal ranges: serum bilirubin $<18 \mu \mathrm{mol} / /$; albumin > $37 \mathrm{~g} / \mathrm{l}$; AT-III 0.85 - $1.50 \mathrm{IE} /$ /; ASAT $<35 \mathrm{U} / \mathrm{l}$

undertaken to determine whether the patients were alive at the time of analysis and this information, including causes of death, was used for analysis.
Table 2: Variceal bleeding

\begin{tabular}{cll}
\hline & $\begin{array}{l}\text { Sclerotherapy } \\
\mathrm{n}=84\end{array}$ & Controls $\mathrm{n}=82$ \\
\hline $\begin{array}{ll}\text { Patients }(\mathrm{n}) \\
\text { Variceal bleeding }\end{array}$ & $21(25 \%)$ & $23(28 \%)$ \\
$\begin{array}{l}\text { Non-variceal bleeding } \\
\text { Episodes }\end{array}$ & $7(8 \%)$ & $7(8.5 \%)$ \\
$\begin{array}{c}\text { Variceal bleeding } \\
\text { All upper Gl-bleeding }\end{array}$ & 32 & 39 \\
$\quad$ Child-Pugh class & 48 & 49 \\
A & $11 / 44$ & $11 / 47$ \\
B & $8 / 32$ & $8 / 25$ \\
C & $2 / 8$ & $4 / 10$ \\
\hline
\end{tabular}

\section{Procedures}

For sixteen patients assigned to undergo ES, treatment was not instituted because of refusal $(n=13)$, concomitant medical problems $(\mathrm{n}=2)$ or miscommunication resulting in failure to initiate ES $(n=1)$. ES was offered to one control patient who repeatedly expressed the explicit wish to be treated because of fear of bleeding. No patient refused to participate in the trial with respect to the prospective recording of follow-up data. During follow-up 9 patients of the control group and 4 of the ES group received a liver transplant. For these cases data were censored at the time of transplantation.

Sclerotherapy resulted in variceal eradication in $47 / 68$ $(69 \%)$ of patients who actually received prophylactic sclerotherapy. The mean volume of sclerosant to achieve eradication was $76 \mathrm{ml}$ (SD 45, range 6-209) and the mean number of sclerotherapy sessions 5.7(SD 2.5, range 214). After eradication varices recurred in $6 / 47(13 \%)$ patients.

\section{Bleeding}

(Table 2) Both the number of patients and the number of episodes of variceal bleeding in the two groups were comparable. The same applied for bleeding due to nonvariceal causes. The incidence of bleeding from varices (Figure 2) for the ES and control groups was 16\% and $16 \%$ at 1 year, $29 \%$ and $29 \%$ at 3 years and $33 \%$ and $35 \%$ at 4 years, respectively (NS). Variceal bleeding occurred in 7 of $16(43 \%)$ patients of the ES group who did not receive therapy. For 10/14 patients of the ES group variceal bleeding occurred early (mean 3.5 months, range 1 day - 9 months), before variceal eradication had been achieved. Two of these patients had a variceal bleeding after randomization but before ES was started. In 4 patients who had ES which resulted in variceal eradication, variceal bleeding occurred after a mean period of 28 months and 5.5 (range 4-9) ES sessions. 


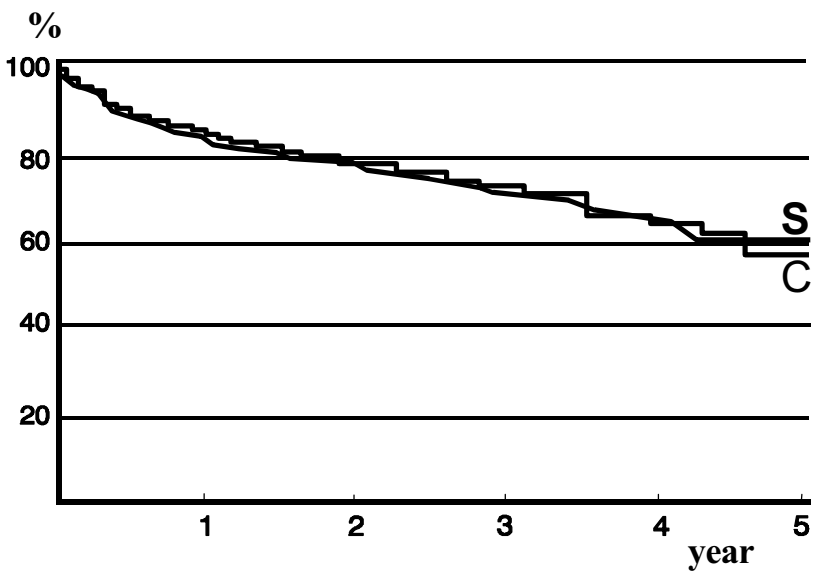

Figure 2

Kaplan-Meier plot showing the percentage of patients free of variceal bleeding (S: sclerotherapy group; C: control group.

Table 3: Causes of death

\begin{tabular}{|c|c|c|}
\hline & $\begin{array}{l}\text { Sclerotherapy } \\
\mathrm{n}=84\end{array}$ & Controls $\mathrm{n}=82$ \\
\hline total & $\mathrm{n}=29$ & $\mathrm{n}=33$ \\
\hline Variceal bleeding & I & 9 \\
\hline Liver failure & 9 & 13 \\
\hline Hepatocellular carcinoma & 5 & 3 \\
\hline \multicolumn{3}{|l|}{ Other causes } \\
\hline Malignancy & 2 & \\
\hline Infection & 4 & 3 \\
\hline Stroke & I & 3 \\
\hline $\begin{array}{l}\text { Bleeding from duodenal } \\
\text { ulcer }\end{array}$ & & I \\
\hline $\begin{array}{l}\text { Postoperative multi- } \\
\text { organ failure }\end{array}$ & I & \\
\hline Hypothermia & I & \\
\hline Esophageal perforation & I & \\
\hline Unknown & 4 & I \\
\hline
\end{tabular}

I complication of sclerotherapy Values are number of patients

Variceal bleeding occurred more frequent in patients with Child class B and C (Table 2), but differences were not statistically significant ( $p=0.9$, log-rank test). For the ES group, the 3-year risk of variceal bleeding for Child A patients was $25 \%$, for Child B patients $32 \%$ and for Child $\mathrm{C}$ patients $34 \%(\mathrm{p}=0.6)$. For control patients the respective percentages were $28 \%, 31 \%$ and $22 \%(p=0.1)$.

The incidence of upper gastrointestinal hemorrhage due to all causes was $22 \%$ for the ES group and $25 \%$ for the

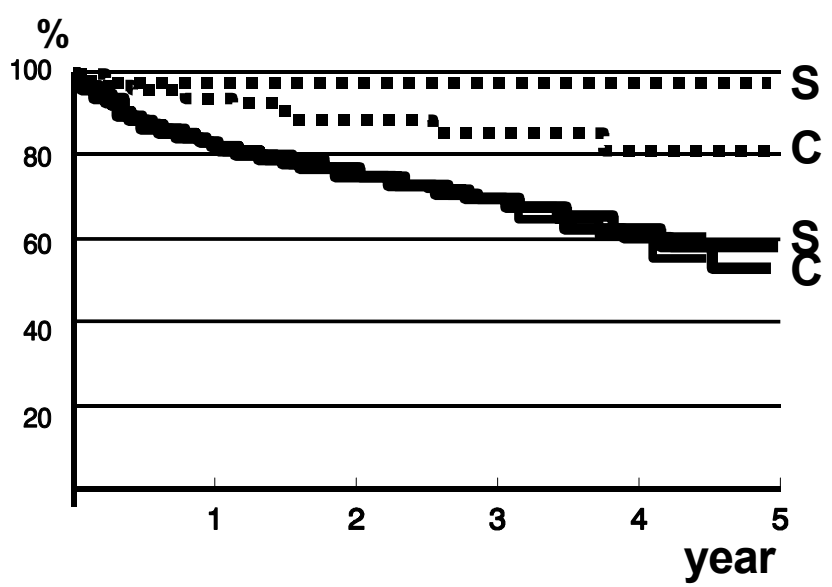

Figure 3

Kaplan-Meier plot showing the percentage of surviving patients (S: sclerotherapy group; C: control group). Overall survival (black lines) was comparable. Mortality due to variceal bleeding (dotted lines) in the sclerotherapy group was significantly lower than in the control group $(p=0.0 \mathrm{I})$

control group after 1 year and 35 and $36 \%$ after 3 years. Per protocol analysis of those patients who underwent the allocated treatment showed that the incidence of variceal hemorrhage for the ES and control group was $17 \%$ and $14 \%$ after 1 year and $19 \%$ and $29 \%$ after 3 years, respectively (NS). The 1 and 2 year incidence of upper gastrointestinal hemorrhage due to all causes was $21 \%$ and $29 \%$ for the ES group and 15\% and 36\% for the control group, respectively (NS).

\section{Mortality}

Twenty-nine (35\%) patients of the ES group died and 33 $(40 \%)$ of the control group (Table 3 ). In the ES group only 1 death occurred as a direct consequence of variceal bleeding compared to 9 in the other group ( $p=0.01$, log-rank test). The frequency of other causes of death was comparable. The 1-year survival rate was $87 \%$ for the ES group and $84 \%$ for the control group; the 3-year survival rate was $62 \%$ for each group (figure 3 ). Univariate analysis showed that 3-year survival for Child-Pugh class A, B and C patients was $77 \%, 45 \%$ and $31 \%(p=0.05)$. For the ES group, survival at 3 years for Child-Pugh class A patients was $86 \%$, for class B patients $38 \%$ and for class $C$ patients $29 \%(p=0.0001)$. For the control group 3 -year survival for class A, B and C was 70\%, 55\% and 31\% (p=0.0001). No relationship was found between mortality and the size of esophageal varices, etiology of liver disease or participating center. 
Table 4: Complications of sclerotherapy

\begin{tabular}{lll}
\hline & $\begin{array}{l}\text { Sclerotherapy } \\
\mathrm{n}=84\end{array}$ & Controls $\mathrm{n}=82$ \\
\hline $\begin{array}{l}\text { Esophagus } \\
\text { Bleeding from ulceration }\end{array}$ & 2 & 3 \\
$\begin{array}{l}\text { Submucosal esophageal } \\
\text { hematoma }\end{array}$ & 2 & \\
$\quad \begin{array}{l}\text { Stenosis } \\
\text { Perforation }\end{array}$ & 2 & 2 \\
$\quad$ Food impaction & $\mathrm{I}$ & \\
$\quad$ Dysphagia & $\mathrm{I}$ & $\mathrm{I}$ \\
Infections & \\
$\quad$ Bacteremia & $\mathrm{I}$ & \\
Bacterial peritonitis & $\mathrm{I}$ & \\
Pneumonia & $\mathrm{I}$ & 6 \\
Total & $\mathrm{II}$ &
\end{tabular}

Values are numbers of patients Complications in the control group occurred after sclerotherapy was performed either to arrest active variceal bleeding or to prevent rebleeding

Per protocol analysis of those patients who underwent the allocated treatment showed that survival for the ES ( $\mathrm{n}=$ $68)$ and control $(n=82)$ group was $85 \%$ and $84 \%$ after 1 year and $61 \%$ and $62 \%$ after 3 years, respectively (NS).

\section{Complications}

Table 4 shows the number of patients who had complications believed to be related to sclerotherapy. Complications for the control group occurred after sclerotherapy was performed for treating acute variceal bleeding or to prevent rebleeding. One fatal complication occurred in a patient of the ES group due to esophageal perforation after two treatment sessions. Two patients developed symptomatic submucosal esophageal hematomas, and in one case this complication was observed on two occasions. In all cases spontaneous and complete resolution ensued. Two to four endoscopic dilatations were required in 3 cases of esophageal stenosis following sclerotherapy; in all cases the symptoms were alleviated. We found no evidence that the frequency of complications differed between centers. $8 / 91$ (9\%) Child-Pugh class A patients suffered a complication compared to $8 / 57(14 \%)$ class B patients and $1 / 18(6 \%)$ class C patients (NS). Thus, no clear relationship was found between the risk of complications and the severity of liver disease.

\section{Costs}

In the University Hospital Rotterdam, 299 upper gastrointestinal procedures were carried out in 41 patients assigned to receive ES, compared to 89 procedures for the control group $(n=40)(p=.0001)$. The mean number of days in hospital was 55 for the ES and 35 for the control patients (NS). The total number of days in hospital was
2277 for the ES group and 1400 for the control group (p $=0.05$ ). The time spent in intensive care (ES group 58, controls 48) was comparable but ES patients spent significantly more time in other wards (2219 vs. 1352 days). The numbers of visits to the outpatient department (ES group: mean 13.4; total 549; control group: mean 12.8; total 512) were comparable. Altogether, these data indicate that ES was the more expensive strategy, suggesting that the initially higher costs of prophylaxis due to hospital admissions and endoscopic procedures were not compensated by potentially decreased medical consumption over time.

\section{Discussion}

In this randomized trial primary prevention of variceal bleeding using endoscopic sclerotherapy did not reduce the bleeding risk for patients with liver cirrhosis and esophageal varices. We found that prophylactic sclerotherapy lowered the risk of fatal variceal bleeding without affecting overall survival. Finally, complications and costs were more marked among patients receiving endoscopic prophylaxis.

Several factors could possibly explain why sclerotherapy was not found to reduce the risk of variceal bleeding in the current trial. We may have failed to detect a real treatment effect, a type II statistical error. Although the sample size of this study seemed adequate, a type II error remains a realistic possibility, in particular because nearly 20\% (16/ 84 ) of patients did not undergo the assigned sclerotherapy treatment. Since the bleeding risk for this particular subgroup was high, this may have diluted the beneficial effects of endoscopic prophylaxis. Although per protocol analysis showed a trend in favor of this possibility, it was not significant. Another factor that could have obscured benefits of ES is an unexpected low bleeding rate for the control group. However, we found that the 3 -year bleeding risk for control patients was very similar to the predicted $30 \%$, and consequently that this factor does not seem of importance. Although this was a randomized trial, one can never guarantee similarity between groups as far as prognostic variables are concerned. Moreover, differences between groups in baseline bleeding risk could be a source of bias. The distribution of variables of prognostic significance in the two groups, particularly ChildPugh scores, age and variceal size, however, make it unlikely that such a bias was important. Sclerotherapy could increase the initial risk of (variceal) bleeding but have a protective effect over time, eventually translating into an overall treatment benefit. We found some evidence to support this possibility since the majority of variceal bleeding episodes were observed before achieving variceal eradication, and bleeding after eradication was a rare event. It has been noted previously that the bleeding risk for patients recruited for trials of prophylactic therapy 

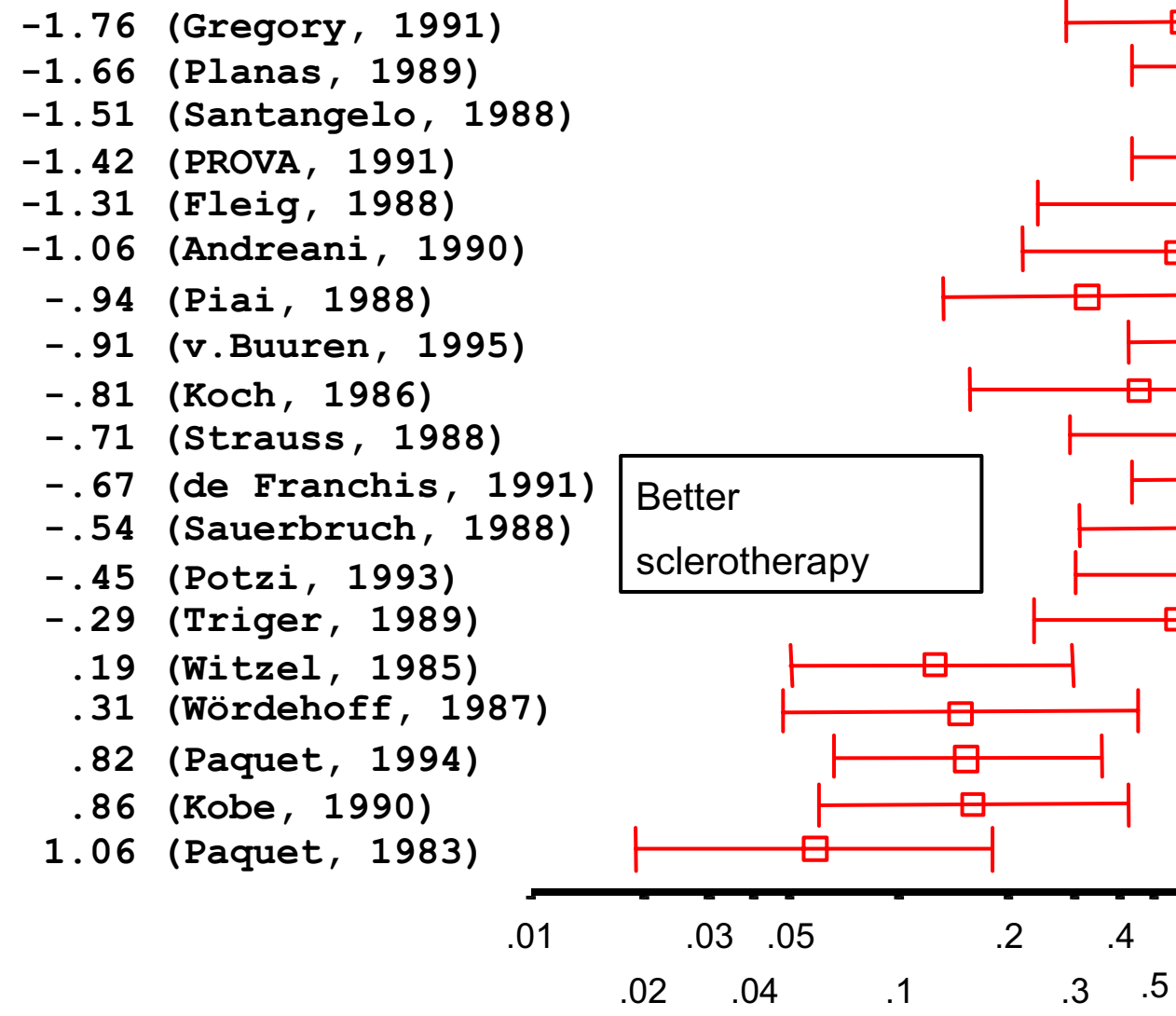

1

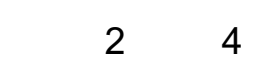

'true' odds

\section{Figure 4}

Meta-analysis (19) of the effect of prophylactic sclerotherapy on the incidence of variceal bleeding. The trials are arranged according to the baseline bleeding-risk, expressed as the odds after logarithmic transformation for the control groups.

seems highest during the first months of follow-up and decreases to about $1 / 3$ after one year [1,3]. This may suggest that, in retrospect, our sclerotherapy protocol was not optimal and a more intensive regimen, resulting in more rapid eradication of varices [20], could have been more effective.

In this trial ES significantly reduced the mortality rate for variceal bleeding, a finding also reported by other groups $[10,20-24]$. In only a few studies, however, was this associated with a corresponding improvement in overall survival $[10,20,21,24]$. In these studies variceal bleeding occurred in at least $50 \%$ of control patients and was the main cause of death, accounting for $65-80 \%$ of mortality. This suggests that the magnitude of the effect of prophylactic sclerotherapy on the risk for variceal bleeding, but also on mortality, is dependent on the baseline bleeding risk. This hypothesis was supported by D'Amico, who found a clear relationship between the effect of sclerotherapy on the incidence of bleeding and the base line bleeding risk as reported in a large number of randomized controlled trials [25]. We also analyzed the relationship between baseline risk and treatment effect using the method proposed by Arends et al. [19]. We found, in agreement with D'Amico's results, that a significant $(\mathrm{p}<$ 0.001 ) relationship exists between the baseline bleeding risk and the effect of treatment when analyzing the results of trials of prophylactic sclerotherapy (Figure 4 and 5), which cannot be attributed to 'regression to the mean'. Thus, endoscopic sclerotherapy is likely to reduce bleeding risk, and probably also mortality, only for patients with a particularly high risk of bleeding. Identification of such patients is possible using the NIEC, or comparable, indices $[26,27]$. For patients with a low bleeding risk, the 


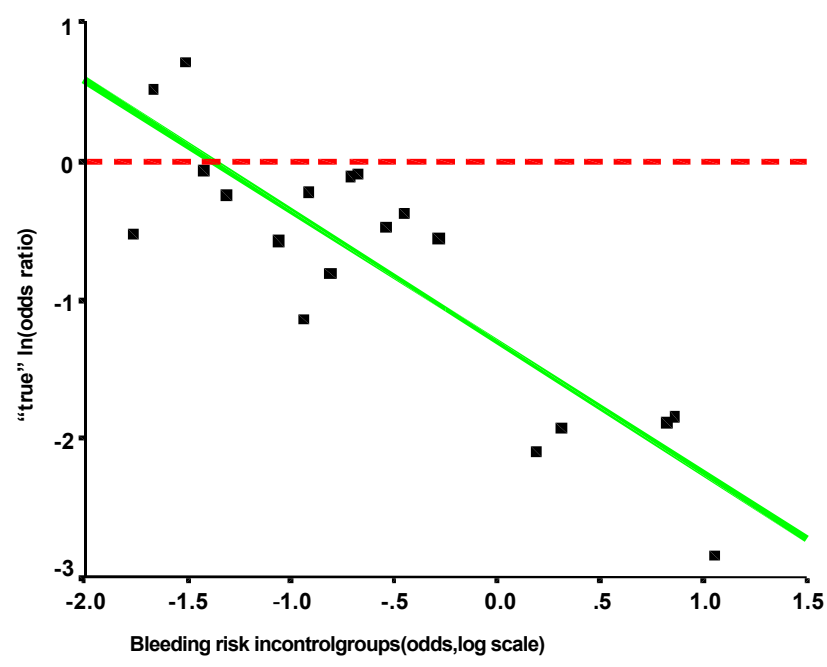

\section{Figure 5}

Meta-analysis (19) of the effect of prophylactic sclerotherapy on the incidence of variceal bleeding. Relationship between Odds ratio for bleeding and the baseline bleeding risk.

effect of sclerotherapy will be marginal or absent; sclerotherapy might even have a deleterious effect. The numerous trials on prophylactic sclerotherapy have been subjected to meta-analysis [28-31]. All studies have produced a statistically significant pooled estimate of treatment effect on bleeding risk and mortality in favor of sclerotherapy. Like the results of the individual studies, the conclusions based upon these analyses have been diverse, varying from an undetermined effect of sclerotherapy $[29,30]$ to sclerotherapy being effective, particularly for high-risk patients $[28,31]$. One meta-analysis [31] yielded a marked difference in the outcome of trials according to the type of sclerosant used, the results clearly favoring polidocanol. The general recommendation emerging from international consensus conferences $[18,32,33]$ has been that sclerotherapy should not be used for primary prophylaxis of variceal bleeding, mainly because of the statistically significant heterogeneity of the treatment effects as observed in studies, and the availability of a non-invasive and cheap alternative (non selective $\beta$-blocker treatment).

When the trial was designed the possibility existed that, as a result of the pre-randomization method, not all patients would accept the assigned treatment. In practice, refusal proved to be a more frequent problem than expected, which complicated the interpretation of results. However, this problem is not unique to the pre-randomization method and similar difficulties can occur with conventional randomization $[3,5,34-36]$. Otherwise, no prob- lems were encountered and our general experience was that the method worked well. Unfortunately, our study design did not allow us to assess whether pre-randomization indeed resulted in increased patient recruitment. Prerandomization has the potential advantage that, at least in theory, all eligible patients will be selected while the conventional method implies that only a selection of eligible patients will be entered. Consequently, the results of trials using this allocation method may have wider applicability.

The observed rate of complications of sclerotherapy in this study is in agreement with previously reported data. In some studies, however, complications were much more frequent $[37,38]$. An explanation for these divergent results remains speculative. Variations in technique [31], technical skill and experience with endoscopic sclerotherapy could at least partially account for some of the reported differences.

Our estimation of costs was based on a proportion of patients and the results obviously are preliminary in nature. Nevertheless, our data suggest that prophylactic treatment was the more expensive option. Taking into account the other findings, the cost/benefit ratio of prophylactic sclerotherapy as applied in this study seems unfavorable.

\section{Conclusions}

The present results does not support the use of sclerotherapy for primary prevention of variceal bleeding when patients are selected according to the criteria we used. Nevertheless, according to cumulative data from a large number of trials, it can be concluded that endoscopic sclerotherapy can result in a significant decrease in the bleeding risk and, probably, also in bleeding-associated mortality, but only in selected cases with a high bleeding risk. On the basis of lower rates of rebleeding, mortality, complications and the need for fewer endoscopic treatments, variceal band ligation has been shown to be superior to sclerotherapy for secondary prophylaxis of variceal bleeding [39]. Several trials have now evaluated band ligation for primary prophylaxis of variceal bleeding. In most, but not all [40], studies band ligation significantly reduced the bleeding risk when compared to control patients [40-42] or administration of propranolol [43], and in one study ligation was also found to improve survival [42]. Additional studies comparing band ligation and non-selective $\beta$-blockers are needed before the role of ligation for primary prevention of variceal bleeding can be defined more precisely. For the time being, $\beta$-blockers remain the principal option for primary prophylaxis of variceal bleeding. For patients with contraindications or intolerance for $\beta$-blockers and for those who are not compliant or do not respond to treatment, variceal band 
ligation rather than sclerotherapy may be considered for primary prophylaxis [44].

\section{Competing interests \\ None declared.}

\section{Authors' contributions}

$\mathrm{HB}$ initiated the study and was the principal investigator, coordinator and author. MR, PB, CB, JN, SW, JS, JH and $E R$ were all involved in the design and the execution of the study. LA and HB performed the statistical analyses. SW conceived of the study and participated in its design and coordination. All authors read and approved of the final manuscript.

\section{Acknowledgements}

We are indebted to Margriet Leeuwesteijn for secretarial assistance. Supported by grant OG 90/006 from the Ziekenfondsraad.

\section{References}

I. Burroughs AK, D'Heygere F and Mclntyre N: Pitfalls in studies of prophylactic therapy for variceal bleeding in cirrhotics. Hepatology 1986, 6: 1407-1413.

2. Baker LA, Smith $C$ and Lieberman G: The natural history of esophageal varices. A study of 115 cirhotic patietns in whom varies were diagnosed prior to bleeding. Am J Med 1959, 26:228-237.

3. Conn HO, Lindenmuth WW, May CJ and Ramsby GR: Prophylactic portacaval anastomosis. A tale of two studies. Medicine (Baltimore) 1972, 5 I:27-40.

4. Resnick RH, Chalmers TC, Ishihara AM, Garceau AJ, Callow AD, Schimmel EM and O'Hara ET: A controlled study of the prophylactic portacaval shunt. A final report. Ann Intern Med 1969, 70:675-688.

5. Jackson FC, Perrin EB, Smith AG, Dagradi AE and Nadal HM: A clinical investigation of the portacaval shunt. II. Survival analysis of the prophylactic operation. Am J Surg 1968, I I 5:22-42.

6. Bernuau J and Rueff B: Treatment of acute variceal bleeding. Clin Gastroenterol 1985, 14:185-207.

7. Graham DY and Lacey Smith J: The course of patients after variceal haemorrhage. Gastroenterology 1981, 80:800-809.

8. Inokuchi K: Improved survival after prophylactic portal nondecompression surgery for esophageal varices: a randomized clinical trial. Hepatology 1990, I 2: I-6.

9. Koch H, Henning H, Grimm H and Soehendra N: Prophylactic sclerosing of esophageal varices--results of a prospective controlled study. Endoscopy 1986, 18:40-43.

10. Witzel L, Wolbergs E and Merki H: Prophylactic endoscopic sclerotherapy of oesophageal varices. A prospective controlled study. Lancet 1985, 1:773-775.

11. Wordehoff $D$ and Spech $H$ ]: [Prophylactic sclerosing of esophageal varices. Results of a prospective randomized 7-year longitudinal study]. Dtsch Med Wochenschr 1987, I I 2:947-95 I.

12. Paquet KJ: Prophylactic endoscopic sclerosing treatment of the esophageal wall in varices -- a prospective controlled randomized trial. Endoscopy 1982, 14:4-5.

13. Terblanche J: Sclerotherapy for prophylaxis of variceal bleeding. Lancet 1986, I:961-963.

14. Oberhammer E, Paquet KJ and Distelmayer W: Endoscopische Befunde bei portaler Hypertension unter Einschlusz der Nottfallenendoskopie. Therapiewoche 1978, 28:

15. Zelen M: A new design for randomized clinical trials. New Eng J Med 1979, 300:1242-1245.

16. Taylor KM, Margolese RG and Soskolne CL: Physician's reasons for not entering eligible patients in a randomiozed controlled trial of surgery for breast cancer. N Engl J Med 1984, 310:1363-1367.
17. Pugh RNH, Murray-Lion IM, L. Dawson J. and al. et: Transection of the oesophagus for bleeding oesophageal varices. $\mathrm{Br}$ J Surg 1973, 60:646-649.

18. de Franchis R, Pascal JP, Ancona E, Burroughs A, Henderson JM, Fleig WE, Groszmann RJ, Bosch J, Sauerbruch T, Soederlund C, Lebrec D, Soerensen TIA and Pagliaro L: Definitions, methodology and therapeutic strategies in portal hypertension. J Hepatol 1992, I5:256-26I.

19. Arends LR, Hoes AW, Lubsen J, Grobbee DE and Stijnen T: Baseline risk as predictor of treatment benefit: three clinical meta-reanalyses. Stat Med 2000, 19:3479-35I8.

20. Paquet KJ, Kalk JF, Klein CP and Gad HA: Prophylactic sclerotherapy for esophageal varices in high-risk cirrhotic patients selected by endoscopic and hemodynamic criteria: a randomized, single-center controlled trial. Endoscopy 1994, 26:734-740

21. Piai G, Cipolletta L, Claar M, Marone G, Bianco MA, Forte G, lodice G, Mattera D, Minieri M, Rocco P and et al.: Prophylactic sclerotherapy of high-risk esophageal varices: results of a multicentric prospective controlled trial. Hepatology 1988, 8: I495-I500.

22. De Franchis R, Primignani M, Arcidiacono PG, Rizzi PM, Vitagliano P, Vazzoler MC, Arcidiacono R, Rossi A, Zambelli A, Cosentino F and et al.: Prophylactic sclerotherapy in high-risk cirrhotics selected by endoscopic criteria. A multicenter randomized controlled trial. Gastroenterology 1991, I0 I:1087-1093.

23. Kobe E, Zipprich B, Schentke KU and Nilius R: Prophylactic endoscopic sclerotherapy of esophageal varices--a prospective randomized trial. Endoscopy 1990, 22:245-248.

24. Paquet KJ: [Sclerotherapy for the prevention of bleeding esophageal varices]. Internist (Berl) 1983, 24:8I-84.

25. D'Amico G: Prognostic stratification in analysis of RCT data. Portal hypertension III. Proceedings of the third Baveno international workshop on definitions, methodology and therapeutic strategies. Edited by: de Franchis R. Oxford, Blackwell Science Ltd; 200I:222-226.

26. Prediction of the first variceal haemorrhage in patients with cirrhosis of the liver and esophageal varices: a prospective multicenter study. N Engl J Med 1988, 31 9:983-989.

27. Merkel C, Zoli M, Siringo S, van Buuren HR, Magalotti D, Angeli P, Sacerdoti $D$, Bolondi $L$ and Gatta $A$ : Prognostic indicators of risk for first variceal bleeding in cirrhosis: a multicenter study in 7 I I patients to validate and improve the North Italian Endoscopic Club (NIEC) index. Am J Gastroenterol 2000, 95:2916-2920.

28. Van Ruiswyk J and Byrd JC: Efficacy of prophylactic sclerotherapy for prevention of a first variceal hemorrhage. Gastroenterology 1992, 102:587-597.

29. D'Amico G, Pagliaro $L$ and Bosch J: The treatment of portal hypertension: a meta-analytic review. Hepatology 1995, 22:332-354.

30. Pagliaro L, D'Amico G, Sorensen TI, Lebrec D, Burroughs AK, Morabito A, Tine F, Politi F and Traina M: Prevention of first bleeding in cirrhosis. A meta-analysis of randomized trials of nonsurgical treatment. Ann Intern Med 1992, I I7:59-70.

31. Fardy JM and Laupacis A: A meta-analysis of prophylactic endoscopic sclerotherapy for esophageal varices. Am J Gastroenterol 1994, 89: 1938-1948.

32. Grace ND, Groszmann RJ, Garcia-Tsao G, Burroughs AK, Pagliaro L, Makuch RW, Bosch J, Stiegmann GV, Henderson JM, de Franchis R, Wagner JL, Conn HO and Rodes J: Portal hypertension and variceal bleeding: an AASLD single topic symposium. Hepatology 1998, 28:868-880.

33. de Franchis R: Developing consensus in portal hypertension. J Hepatol 1996, 25:390-394.

34. Potzi R, Bauer P, Reichel W, Kerstan E, Renner F and Gangl A: Prophylactic endoscopic sclerotherapy of oesophageal varices in liver cirrhosis. A multicentre prospective controlled randomised trial in Vienna. Gut 1989, 30:873-879.

35. Sauerbruch T, Wotzka R, Kopcke W, Harlin M, Heldwein W, Bayerdorffer E, Sander R, Ansari H, Starz I and Paumgartner G: Prophylactic sclerotherapy before the first episode of variceal hemorrhage in patients with cirrhosis. N Engl J Med 1988, 319:8-15.

36. Sclerotherapy after first variceal hemorrhage in cirrhosis. A randomized multicenter trial. The Copenhagen Esophageal Varices Sclerotherapy Project. N Engl J Med 1984, 311:1594-1600. 
37. Santangelo WC, Dueno MI, Estes BL and Krejs G]: Prophylactic sclerotherapy of large esophageal varices. N Engl J Med 1988, 318:814-818.

38. Prophylactic sclerotherapy for esophageal varices in men with alcoholic liver disease. A randomized, single-blind, multicenter clinical trial. The Veterans Affairs Cooperative Variceal Sclerotherapy Group. N Engl J Med |991, 324: $1779-1784$.

39. Laine $L$ and Cook D: Endoscopic ligation compared with sclerotherapy for treatment of esophageal variceal bleeding. A meta-analysis. Ann Intern Med 1995, I 23:280-287.

40. Lo GH, Lai KH, Cheng JS, Lin CK, Hsu PI and Chiang HT: Prophylactic banding ligation of high-risk esophageal varices in patients with cirrhosis: a prospective, randomized trial. J Hepatol 1999, 3 I:45I-456.

4I. Sarin SK, Guptan RK, Jain AK and Sundaram KR: A randomized controlled trial of endoscopic variceal band ligation for primary prophylaxis of variceal bleeding. Eur J Gastroenterol Hepatol 1996, 8:337-342.

42. Lay CS, Tsai YT, Teg CY, Shyu WS, Guo WS, Wu KL and Lo KJ: Endoscopic variceal ligation in prophylaxis of first variceal bleeding in cirrhotic patients with high-risk esophageal varices. Hepatology 1997, 25: I346-1350.

43. Sarin DS, Lamba GS, Kumar M, Misra A and Murthy NS: Comparison of endoscopic ligation and propranolol for the primary prevention of variceal bleeding. N Engl J Med 1999, 340:988-993.

44. de Franchis R: Updating consensus in portal hypertension: report of the Baveno III Consensus Workshop on definitions, methodology and therapeutic strategies in portal hypertension. J Hepatol 2000, 33:846-852.

\section{Pre-publication history}

The pre-publication history for this paper can be accessed here:

http://www.biomedcentral.com/1471-230X/3/22/pre pub

Publish with Bio Med Central and every scientist can read your work free of charge

"BioMed Central will be the most significant development for disseminating the results of biomedical research in our lifetime. "

Sir Paul Nurse, Cancer Research UK

Your research papers will be:

- available free of charge to the entire biomedical community

- peer reviewed and published immediately upon acceptance

- cited in PubMed and archived on PubMed Central

- yours - you keep the copyright 